\title{
Terminal Wiener Index of Fibonacci trees
}

\section{Sulphikar A}

\begin{abstract}
The terminal Wiener index of a tree is defined as the sum of distances between all leaf pairs of T. We derive closed form expression for the terminal Wiener index of fibonacci trees. We also describe a linear time algorithm to compute terminal Wiener index of a tree.
\end{abstract}

Keywords: Terminal Wiener index, fibonacci tree, Pendent vertex, distance in graphs.

\section{INTRODUCTION}

For a tree $T$, the terminal Wiener index TW(T)[7] of $T$ is defined as the sum of the distances between all pairs of leaves of T. That is

$$
T W(T)=\sum_{1 \leq i<j \leq k} d_{T}\left(v_{i}, v_{j}\right)
$$

where $\mathrm{v}_{\mathrm{i}}, \mathrm{v}_{\mathrm{j}}$ are leaves in $\mathrm{T}$.

Let $\mathrm{T}$ be an n-vertex tree with $\mathrm{k}$ leaves. Then $\mathrm{TW}(\mathrm{T})$ can be expressed as

$$
\mathrm{TW}(\mathrm{T})=\sum_{e} \mathrm{p}(\mathrm{e}) \mathrm{p}^{\prime}(\mathrm{e})
$$

where $\mathrm{p}(\mathrm{e})$ and $\mathrm{p}^{\prime}(\mathrm{e})$ are the number of leaves in two components of $\mathrm{T}-\mathrm{e}[6]$. Section 2 outline an algorithmic approach to compute terminal Wiener index of fibonacci trees and binary fibonacci trees. Section 3 explain an algorithm to compute TWI of a tree. The paper[9] describe a method to compute terminal Wiener index of balanced trees.

\section{PROPOSED METHOD}

We propose a method to compute terminal Wiener index of fibonacci trees.

2.1 Fibonacci trees and Binary fibonacci trees

We begin with lemma1 below.

Lemma1:

Let $\mathrm{T}$ be a tree composed of two disjoint trees $T_{1}$ and $T_{2}$ respectively. Let $x \in V\left(T_{1}\right), y \in V\left(T_{2}\right)$ and $x y$ be $a$ cutedge in $\mathrm{T}$. Let $\mathrm{l}_{1}$ and $\mathrm{l}_{2}$ be the number of leaves in $\mathrm{T}_{1}$ and $\mathrm{T}_{2}$ respectively.

For any vertex $u \in \mathrm{V}(\mathrm{T})$ let $\mathrm{d}^{+}(\mathrm{u})$ denote the sum of the distances from $\mathrm{u}$ to every leaf in $\mathrm{T}$. Then $\mathrm{TW}(\mathrm{T})=\mathrm{TW}\left(\mathrm{T}_{1}\right)+\mathrm{TW}\left(\mathrm{T}_{2}\right)+\mathrm{l}_{1} \mathrm{~d}^{+}(\mathrm{y})+\quad \mathrm{l}_{2} \mathrm{~d}^{+}(\mathrm{x})+\mathrm{l}_{1} \mathrm{l}_{2}$. (2) Let $F_{k}$ denote the $k^{\text {th }}$ Fibonacci number. The Fibonacci tree $\mathrm{T}_{\mathrm{fk}}$ of order $\mathrm{k}[2,10]$, is defined recursively in the following way:

$\mathrm{T}_{\mathrm{f}-1}$ and $\mathrm{T}_{\mathrm{f} 0}$ are both fibonacci trees consisting of a single node. For $\mathrm{k}>=1, \mathrm{~T}_{\mathrm{fk}}$ consist of two fibonacci trees $\mathrm{T}$ fk-1 and $T_{\text {fk-2 }}$ of orders k-1 and k-2 respectively, where $T$ fk-2 is the rightmost child of the root of the other.

Revised Manuscript Received on February 05, 2020.

* Correspondence Author

Sulphikar A*, Department of Computer Science and Engineering, National Institute of Technology, Trichy, Tamilnadu INDIA

(c) The Authors. Published by Blue Eyes Intelligence Engineering and Sciences Publication (BEIESP). This is an open access article under the CC BY-NC-ND license (http://creativecommons.org/licenses/by-nc-nd/4.0/)
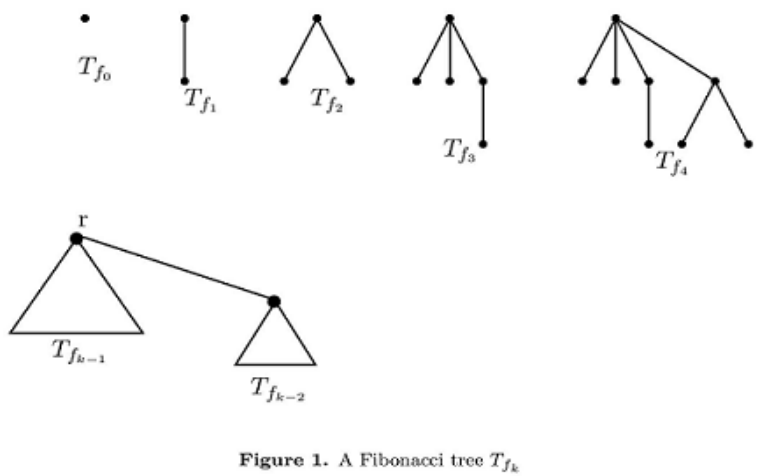

Let $\mathrm{T}_{\mathrm{fk}} \mathrm{b}$ denote the binary Fibonacci tree of order $\mathrm{k}[2,10]$, is defined recursively in the following way:

$\mathrm{T}_{\mathrm{f} 0} \mathrm{~b}$ and $\mathrm{T}_{\mathrm{f} 1}{ }^{\mathrm{b}}$ are both rooted trees consisting of no nodes and a single node respectively.

For $\mathrm{k}>=2, \mathrm{~T}_{\mathrm{fk}} \mathrm{b}$ consist of a root with two fibonacci trees, $\mathrm{T}_{\mathrm{fk}-}$ ${ }_{1}^{\mathrm{b}}$ and $\mathrm{T}_{\mathrm{fk}-2} \mathrm{~b}$ as left and right child respectively.

Figure 2 shows binary fibonacci trees $\mathrm{T}_{\mathrm{f} 1}{ }^{\mathrm{b}}$ through $\mathrm{T}_{\mathrm{f} 4} \mathrm{~b}$.

Terminal Wiener index of a Fibonacci tree

Theorem 2.1

Let $\mathrm{T}_{\mathrm{fk}}$ be a fibonacci tree. Then its terminal Wiener index is given by

$\mathrm{TW}\left(\mathrm{T}_{\mathrm{fk}}\right)=\mathrm{TW}\left(\mathrm{T}_{\mathrm{fk}-1}\right)+\mathrm{TW}\left(\mathrm{T}_{\mathrm{fk}-2}\right)+\mathrm{F}_{\mathrm{k}} \mathrm{d} \quad \mathrm{Tf}^{+}(\mathrm{k}-2)+\mathrm{F}_{\mathrm{k}-1} \quad \mathrm{~d}_{\mathrm{Tf}}{ }^{+}(\mathrm{k}$ 1) $+F_{k} F_{k-1}, k \geq 3$ (3)

where $\mathrm{k}$ is its order.

$\bullet$
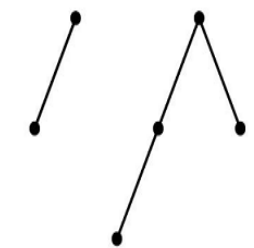

$T_{f_{1}}^{b} \quad T_{f_{2}}^{b}$
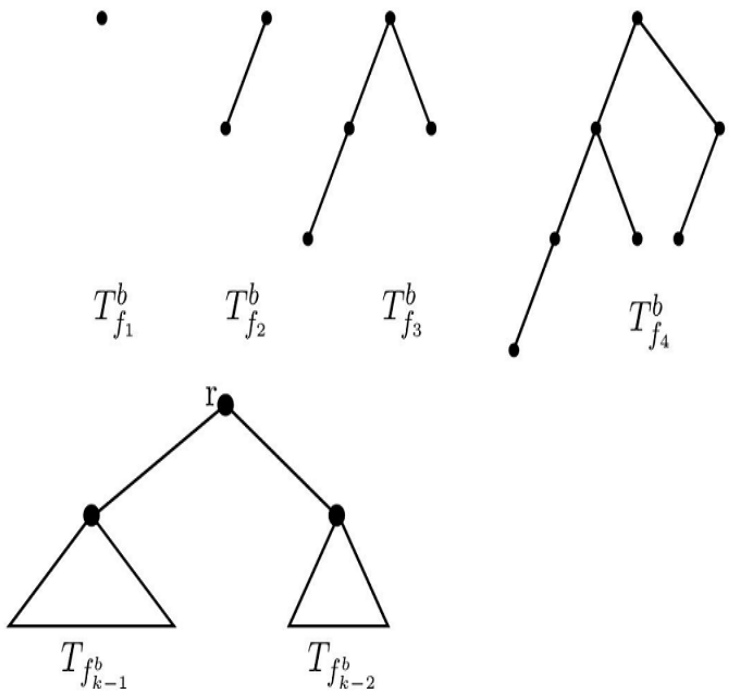

Figure 2. Binary Fibonacci tree $T_{f_{k}}^{b}$

Proof.

In order to compute $\mathrm{TW}\left(\mathrm{T}_{\mathrm{fk}}\right)$, we first obtain a closed form expression for $\mathrm{d}^{+} \mathrm{Tf}(\mathrm{k})$, sum of the distance between root of $\mathrm{T}_{\mathrm{f}}(\mathrm{k})$ and its leaves. 


\section{Terminal Wiener Index of Fibonacci trees}

From fig.1, we have

$\mathrm{d}^{+} \mathrm{Tf}(\mathrm{k})=\mathrm{d}^{+}{ }_{\mathrm{Tf}}(\mathrm{k}-1)+\mathrm{d}^{+} \mathrm{Tf}(\mathrm{k}-2)+\mathrm{F}_{\mathrm{k}-1}, \quad$ (4)

with $\mathrm{d}^{+} \mathrm{Tf}(0)=0, \mathrm{~d}^{+} \mathrm{Tf}(1)=1$, and $\mathrm{d}^{+} \mathrm{Tf}(2)=2$.

We introduce the generating function $G(z)$ as

$\mathrm{G}(\mathrm{z})=\mathrm{d}^{+}{ }_{\mathrm{Tf}}(1) \mathrm{z}+\mathrm{d}^{+}{ }_{\mathrm{Tf}}(2) \mathrm{z}^{2}+\mathrm{d}^{+}{ }_{\mathrm{Tf}}(3) \mathrm{z}^{3}+\mathrm{d}^{+}{ }_{\mathrm{Tf}}(4) \mathrm{z}^{4}+\ldots$

(5)

2.2

From (eq:4) and (eq:5) we get

$\left(1-\mathrm{z}-\mathrm{z}^{2}\right) \mathrm{G}(\mathrm{z})=1+\mathrm{F}_{1} \mathrm{z}+\mathrm{F}_{2} \mathrm{Z}^{2}+\mathrm{F}_{3} \mathrm{Z}^{3}+\mathrm{F}_{4} \mathrm{z}^{4}+\ldots=1+\frac{z}{1-z-z^{2}}$

(6)

$\mathrm{G}(\mathrm{z})$ can be obtained from (eq:6) as

$\left.\mathrm{G}(\mathrm{z})=1 /\left(1-\mathrm{z}-\mathrm{z}^{2}\right)+\left(1-\mathrm{z}-\mathrm{z}^{2}\right)^{2}\right\}=1 / 5 \mathrm{z}\left(1 /(1-\varphi \mathrm{z})^{2}+1 /(1-\right.$

$\left.\left.\varphi^{\prime} \mathrm{z}\right)^{2}\right\}+4 \mathrm{z} /\left(1-\mathrm{z}-\mathrm{z}^{2}\right)$

where $\varphi=(1+\sqrt{5}) / 2$ and $\varphi^{\prime}=(1-\sqrt{5}) / 2$.

It follows(see [8]) that $\mathrm{k}+1$

$\left[\mathrm{z}^{\mathrm{k}}\right] \mathrm{G}(\mathrm{z})=\mathrm{d}^{+}{ }_{\mathrm{Tf}}(\mathrm{k})=\mathrm{F}_{\mathrm{k}}+\sum \mathrm{F}_{\mathrm{j}-1} \mathrm{~F}_{\mathrm{k}-\mathrm{j}+1}=\frac{1}{5}\left[(\mathrm{k}+4) \mathrm{F}_{\mathrm{k}}+2 \mathrm{kF}_{\mathrm{k}-1}\right]$. $\mathrm{j}=2$

substituting $\mathrm{l}_{1}=\mathrm{F}_{\mathrm{k}}$ and $\mathrm{l}_{2}=\mathrm{F}_{\mathrm{k}-1}$ in lemma1 we get

$\operatorname{TW}\left(\mathrm{T}_{\mathrm{fk}}\right)=\mathrm{TW}\left(\mathrm{T}_{\mathrm{fk}-1}\right)+\mathrm{TW}\left(\mathrm{T}_{\mathrm{fk}-2}\right)+\mathrm{F}_{\mathrm{k}} \mathrm{d}_{\mathrm{Tf}}{ }^{+}(\mathrm{k}-2)+\mathrm{F}_{\mathrm{k}-1} \quad \mathrm{~d}_{\mathrm{Tf}}{ }^{+}(\mathrm{k}-$

1) $+\mathrm{F}_{\mathrm{k}} \mathrm{F}_{\mathrm{k}-1}, \mathrm{k}>=3$

with $\operatorname{TW}\left(\mathrm{T}_{\mathrm{f} 1}\right)=0$ and $\operatorname{TW}\left(\mathrm{T}_{\mathrm{f} 2}\right)=2$.

The following algorithm computes $\mathrm{TW}\left(\mathrm{T}_{\mathrm{fk}}\right)$.

1.Procedure TWI-FIB $(\mathrm{k})$

2. For $\mathrm{i}=1$ to $\mathrm{k}$ do

3. Compute $\mathrm{F}_{\mathrm{i}}$

4. $\mathrm{TW}_{1}=0$

5. $\mathrm{TW}_{2}=2$

6. For $\mathrm{j}=3$ to $\mathrm{k}$ do

7. $\mathrm{D}=0.2\left((\mathrm{j}+3) \mathrm{F}_{\mathrm{j}-1}+2(\mathrm{j}-1) \mathrm{F}_{\mathrm{j}-2}\right)$

8. $\mathrm{D}^{\prime}=0.2\left((\mathrm{j}+2) \mathrm{F}_{\mathrm{j}-2}+2(\mathrm{j}-2) \mathrm{Fj}-3\right)$

9. $\mathrm{TW}=\mathrm{TW}_{1}+\mathrm{TW}_{2}+\mathrm{F}_{\mathrm{j}-1} \mathrm{D}+\mathrm{F}_{\mathrm{j}} \mathrm{D}^{\prime}$

10. $\mathrm{TW}_{1}=\mathrm{TW}_{2}$

11. $\mathrm{TW}_{2}=\mathrm{TW}$

12. return TW

13. EndProcedure

Theorem 2.2

For a fibonacci tree of order $\mathrm{k}$ denoted by $\mathrm{T}_{\mathrm{fk}}$ we can compute $\mathrm{TW}\left(\mathrm{T}_{\mathrm{fk}}\right)$ in $\mathrm{O}\left(\log \mathrm{F}_{\mathrm{k}}\right)$ time.

Proof.

It is easy to see that in TWI-FIB(k) step 2 requires atmost $\log F_{k}$ additions and steps 7-12 require atmost $\log F_{k}$ multiplications and additions.

2.3 Terminal Wiener index of a Binary fibonacci tree

Theorem 2.3

Let $\mathrm{T}_{\mathrm{fk}}^{\mathrm{b}}$ be a binary fibonacci tree of order $\mathrm{k}[10]$. Then its terminal Wiener index is given by

$\mathrm{TW}\left(\mathrm{T}_{\mathrm{fk}}{ }^{\mathrm{b}}\right)=\mathrm{TW}\left(\mathrm{T}_{\mathrm{fk}-1}{ }^{\mathrm{b}}\right)+\mathrm{TW}\left(\mathrm{T}_{\mathrm{fk}-2}{ }^{\mathrm{b}}\right)+\mathrm{F}_{\mathrm{k}-1} \mathrm{~d}_{\mathrm{Tf}}^{\mathrm{b}+}(\mathrm{k}-2)+\mathrm{F}_{\mathrm{k}-2} \mathrm{~d}_{\mathrm{Tf}}{ }^{\mathrm{b}+}(\mathrm{k}-$

1) $+\mathrm{F}_{\mathrm{k}-1} \mathrm{~F}_{\mathrm{k}-2}, \mathrm{k} \geq 4$.

Proof.

Consider the Fibonacci tree $\mathrm{T}_{\mathrm{fk}}$ of fig.2 . In computing $\operatorname{TW}\left(\mathrm{T}_{\mathrm{fk}}\right)$, we first obtain a closed form expression for $\mathrm{d}^{+} \mathrm{Tf}^{\mathrm{b}}(\mathrm{k})$. From fig. Iref \{fig:7\}, we have

$\mathrm{d}^{+} \mathrm{Tf} \mathrm{b}(\mathrm{k})=\mathrm{d}^{+} \mathrm{Tf}^{\mathrm{b}}(\mathrm{k}-1)+\mathrm{d}^{+} \mathrm{Tf}^{\mathrm{b}}(\mathrm{k}-2)+\mathrm{F}_{\mathrm{k}}$,

with $\mathrm{d}^{+} \operatorname{Tf}^{\mathrm{b}}(0)=0, \mathrm{~d}^{+} \mathrm{Tf}^{\mathrm{b}}(1)=0$, and $\mathrm{d}^{+}{ }_{\mathrm{Tf}}^{\mathrm{b}}(2)=1$.

Using method similar to section 2.2, we get

$\left[\mathrm{z}^{\mathrm{k}}\right] \mathrm{G}(\mathrm{z})=\mathrm{d}^{+}{ }_{\mathrm{Tf}}^{\mathrm{b}}(\mathrm{k})=\sum_{j=1}^{k+1} F j F k-j+1-F k$

$=\frac{1}{5}\left[\mathrm{kF}_{\mathrm{k}+2}+(\mathrm{k}-3) \mathrm{F}_{\mathrm{k}}\right]$.

By taking $\mathrm{l}_{1}=\mathrm{F}_{\mathrm{k}-1}$ and $\mathrm{l}_{2}=\mathrm{F}_{\mathrm{k}-2}$, by lemma1 we get

$\left.\operatorname{TW}\left(\mathrm{T}_{\mathrm{fk}}^{\mathrm{b}}\right)=\mathrm{TW}\left(\mathrm{T}_{\mathrm{fk}-1}{ }^{\mathrm{b}}\right)+\mathrm{TW}\left(\mathrm{T}_{\mathrm{fk}-2} \mathrm{~b}\right\}\right)+\mathrm{F}_{\mathrm{k}-1} \mathrm{~d}_{\mathrm{Tf}}^{\mathrm{b}}{ }^{\mathrm{b}}(\mathrm{k}-2)+\mathrm{F}_{\mathrm{k}-2}$
$\mathrm{d}_{\mathrm{Tf}}^{\mathrm{b}+}(\mathrm{k}-1)+\mathrm{F}_{\mathrm{k}-1} \mathrm{~F}_{\mathrm{k}-2}, \mathrm{k} \geq 4$.

with $\operatorname{TW}\left(\mathrm{T}_{\mathrm{f} 2}{ }^{\mathrm{b}}\right)=0$ and $\operatorname{TW}\left(\mathrm{T}_{\mathrm{f} 3}{ }^{\mathrm{b}}\right)=3$.

Using eq:9 we can compute $\operatorname{TW}\left(\mathrm{T}_{\mathrm{fk}} \mathrm{b}\right)$ similar to the algorithm TWI-FIB(k).

\section{AN ALGORITHM TO COMPUTE TERMINAL WIENER INDEX}

We outline an algorithm to compute TWI of a tree T, which uses tree reduction and vertex weighting. Each vertex $u$ is assigned two weights, $\mathrm{w}[\mathrm{u}]$ and $\mathrm{w}^{\prime}[\mathrm{u}]$.

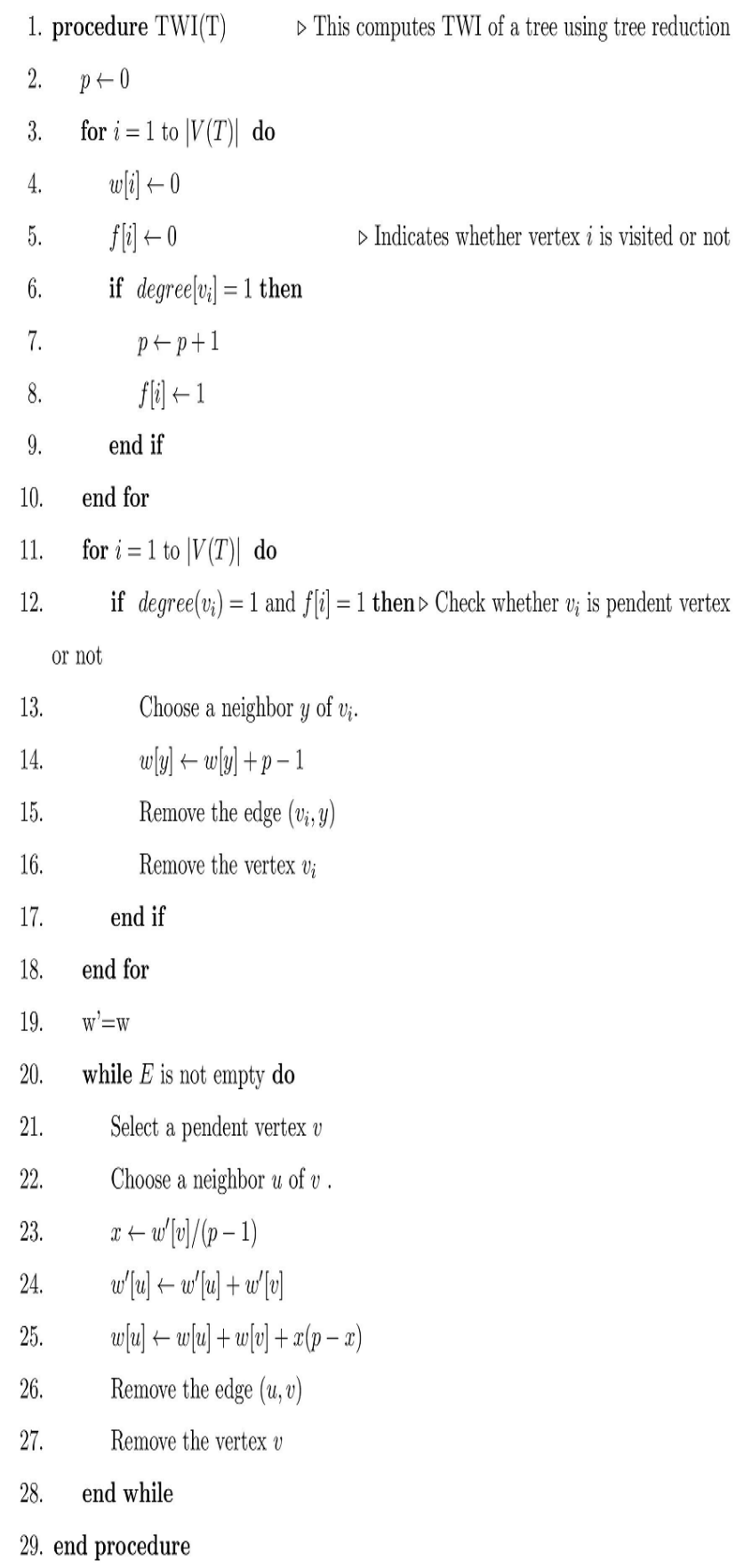

The best case occurs if $\mathrm{T}$ is a star and the worst case occurs if $\mathrm{T}$ is a path. If the $\mathrm{T}$ is a star, the while loop in lines 20-28 is not executed at all. The maximum number of iterations for both while loops together can not exceed the number of vertices in T. Therefore, the complexity of the above algorithm is $O(n)$. 


\section{IV.RESULT ANALYSIS}

The above algorithm is implemented using Python 2.7 and NetworkX. The input to the algorithm is a tree and the tree is reduced by removing pendent vertices one at a time. Each time a pendent vertex is removed, the weights are updated. Finally the tree reduces to single vertex, in which case its weight gives TWI of the tree. Fig.3 shows a tree with terminal Wiener index $=82$ and Table 1 list the values of $\mathrm{w}$ and w' during the execution of the algorithm.

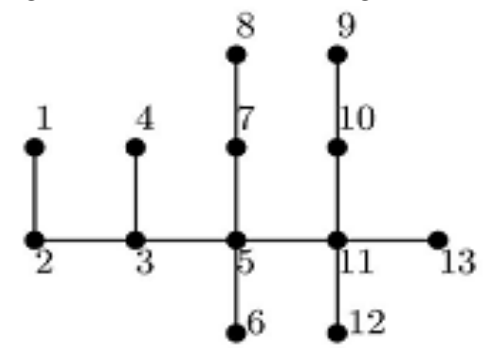

Figure 3. A tree $T$ with $T W(T)=82$

\begin{tabular}{|c|c|c|c|}
\hline vertex(v) & edge(v-u) & w(u) & w'(u) \\
\hline 1 & $1-2$ & 6 & - \\
4 & $4-3$ & 6 & - \\
8 & $8-7$ & 6 & - \\
6 & $6-5$ & 6 & - \\
9 & $9-10$ & 6 & - \\
12 & $12-11$ & 6 & - \\
13 & $13-11$ & 12 & - \\
2 & $2-3$ & 18 & 12 \\
3 & $3-5$ & 34 & 18 \\
7 & $7-5$ & 46 & 24 \\
10 & $10-11$ & 24 & 18 \\
5 & $5-11$ & 82 & 42 \\
\hline
\end{tabular}

Table 1. Steps for computing TWI of tree in fig.3

\section{V.CONCLUSION}

This paper introduces an efficient way to compute terminal Wiener index of Fibonacci trees and binary fibonacci trees. For fibonacci trees, we developed an algorithm to compute TWI in $\mathrm{O}(\log (\mathrm{Fk}))$ time. We also intoduced an algorithm for computing TWI of any tree in linear time.

\section{REFERENCES}

1. Y. H. Chen, X. D. Zhang(2013) On Wiener and terminal Wiener indices of trees, MATCH Commun. Math. Comput. Chem. 70, 591-602.

2. T. H. Cormen, C. E. Leiserson and R. L. Rivest(1994) Introduction to Algorithms, The MIT Press.

3. P. Dankelmann(1993) Computing the average distance of an interval graph, Inform. Process. Lett. 48, 311-314.

4. A.A. Dobrynin, R. Entringer, I. Gutman(2001) Wiener index of trees: theory and applications, Acta Appl. Math. 66, 211-249.

5. A. A. Dobrynin, I. Gutman, S. Klavazar and P. Zigert(2002) Wiener index of hexagonal sytems, Acta Appl. Math. 72, 247-294.

6. I. Gutman and B. Furtula(2010) A survey on terminal Wiener index, in I. Gutman and B. Furtula(Eds.) Novel Molecular Structure Descriptors - Theory and Applications, Kragujevac, 173-190.

7. I. Gutman, B. Furtula and M. Petrovic(2009) Terminal Wiener index, J. Math. Chem. 46, 522-531.

8. D. E. Knuth The Art of Computer Programming. vol. 1, 3/e, AddisonWesley, 1997.

9. A Sulphikar(2019) Terminal wiener index of balanced trees. vol. 8, Int'l Journal of Recent Technology and Engg, 2270-74.

10. K. Viswanathan Iyer, K. R. Uday Kumar Reddy(2009) Wiener index of binomial trees and Fibonacci trees, Int'l. J. Math. Engg. with Comp.

11. The distances between internal vertices and leaves of a tree, European Journal of Combinatorics, 41, 79-99.

\section{AUTHORS PROFILE}

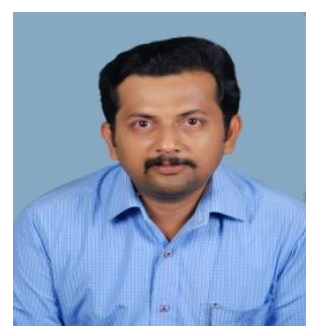

Mr.Sulphikar.A B.Tech, M.Tech is doing Ph.D at National institute of technology, Tiruchirappalli, Tamilnadu,India. His research areas include algorithms and graph theory. 